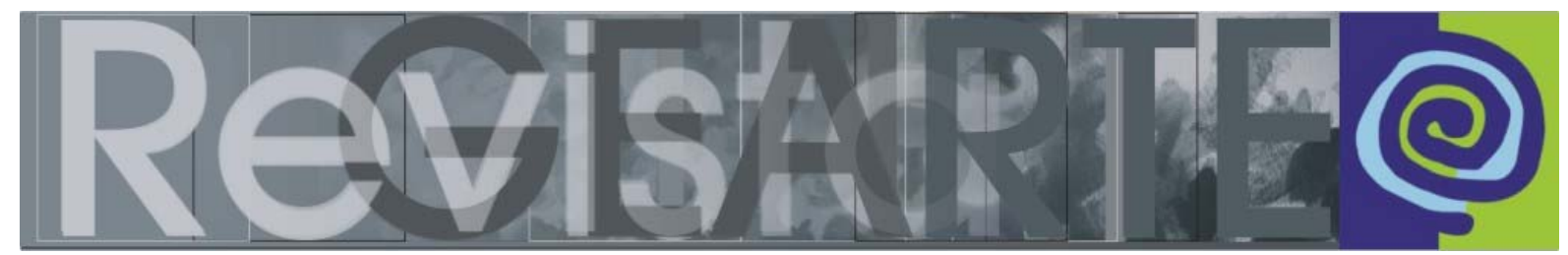

ISSN 2357-9854

\title{
A capacidade de uma batalhadora para impulsionar o ensino da arte na América Latina ${ }^{1}$
}

\author{
Ricard Huerta (Universidade de Valência - Espanha)
}

\begin{abstract}
RESUMO
Este artigo apresenta e discute a pesquisa "Redesenhando o desenho: educadores, política e história", desenvolvida por Ana Mae Barbosa, ao longo de mais de dez anos, sobre a modernização do ensino das artes visuais e do desenho no período de 1920 a 1950 no Brasil, feita principalmente em jornais da época. Evidencia as políticas educacionais e importantes educadores que defenderam a inserção da visualidade baseada na cultura local na educação. Relaciona tal modernização com o movimento modernista no ensino do Desenho realizado em outros países da América Latina, como no México e no Peru.
\end{abstract}

PALAVRAS-CHAVE

Ensino da arte. Políticas educacionais. História do ensino da arte.

\section{RESUMEN}

Este artículo presenta y discute la investigación "Redesenhando o Desenho: educadores, política e história", desarrollada por Ana Mae Barbosa, durante más de diez años acerca da modernización de la educación artística y del dibujo en el período de 1920 a 1950 en Brasil, realizada principalmente en los periódicos de la época. Destaca las políticas educativas y los educadores importantes que defendían la inclusión de la visualidad basada en la cultura local en la educación. Relaciona esta modernización con el movimiento modernista en la enseñanza del dibujo hecho en otros países latinoamericanos como México y Perú.

\section{PALABRAS CLAVE}

Educación artística. Políticas educativas. Historia de la educación artística.

A leitura do livro Redesenhando o Desenho: educadores, política e história de Ana Mae Barbosa supõe uma imersão nas políticas educacionais que regem nosso campo de referência. A presença de Ana Mae no cenário internacional do ensino da arte é importante, tanto quanto sua trajetória e luta durante mais de cinco décadas, buscando e conseguindo dignificar nossa área de conhecimento. Presidiu a $\operatorname{InSEA}^{2}$ e fomentou um encontro frutífero entre as diferentes sensibilidades ibero-americanas, tentando unificar esforços para promover as artes nos programas educativos governamentais. Também é

1 Uma versão deste trabalho foi publicada em espanhol em: <http://www.redclea.org/wpcontent/uploads/2015/11/Rese\%C3\%B1a-Libro-Ana-Mae-Barbosa-por-Richard-Huerta.pdf $>$.

2 International Society for Education through Art.

HUERTA, Ricard. A capacidade de uma batalhadora para impulsionar 339 o ensino da arte na América Latina.

Revista GEARTE, Porto Alegre, v. 2, n. 3, p. 339-344, dez. 2015.

Disponível em: http://seer.ufrgs.br/gearte 
preciso reconhecer seu constante empenho em unir e visibilizar a classe de arte/educadores.

Este magnífico ensaio constrói um discurso no qual é reivindicado o papel das pessoas que se destacaram por suas conquistas no último século. Aqui são vinculados os feitos históricos à atualidade mais recente, de maneira que também incide sobre as disputas pessoais e as lutas internas que diversas vezes sufocam as vozes mais interessantes do panorama atual, criticando as políticas de "terra arrasada" daqueles obstinados em eliminar as conquistas de quem nos precedeu, a fim de anular a memória daquilo que nos pertence como patrimônio. A autora estrutura este impressionante trabalho em períodos históricos e insiste em reclamar um papel relevante para o ensino da arte em seu país, centrando sua pesquisa em alguns dos autores mais destacados. Desta forma, organiza um esquema por partes em que Theodoro Braga representa a virada industrial do início do século XX; enquanto Cecília Meireles e Edgar Sussekind de Mendonça representariam a virada modernista, num período notadamente influenciado por autores anglo-saxões advindos, tanto do âmbito estadunidense (John Dewey e Viktor Lowenfeld do Teachers College, da Columbia University) quanto do britânico (Marion Richardson e Herbert Read, da Inglaterra). Não podemos esquecer que a tese de doutorado de Ana Mae Tavares Bastos Barbosa foi defendida na Universidade de Boston, em 1979, e é intitulada American influences on Art Education in Brazil: analyses of two moments: Walter Smith and John Dewey. Apesar de no livro adquirir maior presença o período histórico que compreende as décadas da primeira metade do século $X X$, as reflexões da autora nos aproximam constantemente da atualidade. A leitura deste volume consegue emocionar, e acredito que conseguiu equilibrar tanto um exercício de memória histórica com a necessária reflexão crítica que vê o presente e se projeta nas possibilidades de futuro.

Cada capítulo é precedido por uma epígrafe. Trata-se, portanto, de 14 exemplos escolhidos, graças aos quais podemos vislumbrar alguns aspectos que constroem a poderosa personalidade da autora do livro, tanto no que se refere à sua presença social como naquilo que concerne à sua intimidade. Chamou-me a atenção que a epígrafe do capítulo 14 fosse um texto de Barbara 
Kruger. Minha admiração pela artista me encorajou a perguntar à própria Ana Mae sobre esta decisão, e ela me respondeu que havia conhecido pessoalmente Barbara Kruger quando organizou uma exposição sua em São Paulo. É que por quase uma década nossa autora foi diretora do poderoso MAC (Museu de Arte Contemporânea) da USP (Universidade de São Paulo). A relação desta cidade, capital econômica e financeira do Brasil, com o universo da arte vem de longe. De fato, a Bienal de São Paulo, que iniciou seu percurso em 1951, é um dos encontros mais prestigiados e relevantes do panorama mundial da arte. Outro aspecto importante que nos revela esta citação de Kruger ("The new history is not only about the pain of the past, or the struggles of the present...") é também uma das facetas pela qual Ana Mae sempre se destacou: sua indefectível defesa dos direitos das mulheres. A ênfase que nossa autora imprime em suas ações sempre foi ancorada em um olhar feminista que se faz necessário em um país no qual as conquistas das pessoas do sexo feminino são acompanhadas de grandes esforços, tanto no âmbito pessoal como quando se trata de reinvindicações sociais, havendo demonstrado sua coragem para conseguir novas vitórias econômicas, legais ou inclusive sanitárias. A paixão com que descreve a figura de Cecília Meireles (a quem dedica o capítulo 7) é uma mostra dessa deriva feminista de sua trajetória, e na obra da educadora encontramos muitos pontos de encontro com algumas das reivindicações mais urgentes do ensino da arte: a paixão pelo cinema, a incidência na formação infantil, o esforço em relacionar as culturas da Ibero-América, o papel da mediação nos museus ou, ainda, a transversalidade que nos permite encontros frutíferos com as outras áreas do currículo, especialmente com a literatura e as ciências sociais.

No texto destaca-se o trabalho de personalidades ibero-americanas do ensino da arte durante a primeira metade do século XX: Gerardo Seguel, no Chile; Adolfo Best Maugard, no México; ou Elena Izcue, no Peru. Também reúne nomes de personalidades que se destacaram em períodos mais recentes: Manuel Pantigoso, no Peru; Luís Errazuriz, no Chile; Salomón Aznar, no Uruguai; Ramón Cabrera, em Cuba; Olga Olaya, na Colômbia; ou Lucia Pimentel, no Brasil; os quais constituem o núcleo primário do CLEA (Conselho Latinoamericano de Educação através da Arte). Ao longo da obra, destaca os aportes 
teóricos que impulsionam Ricardo Marín nas Arts Based Research ou Imanol Aguirre na Cultura Visual, sem esquecer a sintonia que o une aos pesquisadores de Girona: Roser Juanola e Joan Vallés. Barbosa defende, com bastante entusiasmo, um panorama respeitoso com a tradição, no qual se possa estabelecer critérios novos, ajudando a difundir as ideias das gerações de pesquisadores mais jovens, superando assim os preconceitos que possam enfrentar as diferentes escolas, tendências ou departamentos universitários. Não devemos perder de vista que nossa autora pesquisou durante um ano no Centre for Contemporary Cultural Studies da Universidade de Birmingham, compartilhando trabalhos com Richard Hoggart, o qual havia fundado em 1963, junto com Stuart Hall, esse prestigioso instituto universitário pioneiro dos estudos culturais. A autora apoia a abordagem dos Estudos Visuais como aporte teórico para as pesquisas em nosso campo de atuação, mas sem perder de vista o rico panorama que nos precede. Companheira de esforços junto a Paulo Freire e ativista consciente do papel social e de defesa dos direitos humanos que devem impulsionar o ensino da arte, Barbosa sabe que as diferenças foram uma das fontes mais fecundas da evolução de nossa área de conhecimento. A própria palavra "desenho", que no Brasil também serviu para denominar o que agora entendemos por "design" (design gráfico ou de produto), é uma das numerosas acepções polissêmicas às quais devemos nos acostumar. Ocorre em muitos âmbitos específicos do ensino da arte, que nomes e conceitos vão flutuando com o tempo. Um bom exemplo deste tipo de diferença pode ser visto na seguinte reflexão:

Curiosamente, ao contrário das outras formas de Arte, o cinema foi introduzido nas escolas como cultura para ser visto e analisado, e só depois se estimulou o cinema como expressão, como criação, como um fazer nas salas de aula. As outras Artes Visuais, como Pintura, Desenho, Escultura, Gravura, Instalações, etc., foram introduzidas nas escolas como expressão pelo modernismo, e só depois com o pósModernismo entraram nas escolas como cultura a ser decodificada, fruída e significada. (BARBOSA, 2015, p. 251-252).

O método de trabalho que Barbosa utiliza para revisar os diferentes momentos históricos consiste em reproduzir artigos de jornais ou outros documentos peculiares, como entrevistas inéditas, ou, ainda, lança à luz manuscritos encontrados em bibliotecas, folhetos e gravações que haviam 
permanecido ocultos por décadas. Graças a essa busca em diversas mídias, Barbosa pôde ir construindo uma estrutura que leva em conta algo além dos livros e dos textos habituais. Tudo isso sem deixar de valorizar a impressionante bagagem pessoal que a precede, já que Ana Mae é uma profissional inquieta, muito presente nos congressos e reuniões científicas, com um desejo incansável de conhecer o que está ocorrendo em cada lugar do planeta. Ao ter garimpado em acervos e bibliotecas pouco pesquisadas até agora, a autora se transforma em historiadora crítica, já que manuseia fontes amplas, destacando sua preferência por artigos encontrados nas hemerotecas consultadas. Em alguns momentos, apresenta-nos os textos tal e qual foram publicados, insistindo no fato de que eles mesmos dizem muito mais do que aquilo que ela poderia explicar. Deste modo, também podemos saborear os documentos autênticos redigidos por Fernando de Azevedo, Theodoro Braga, Cecília Meireles, John Dewey ou Herbert Read. Aqui, Barbosa sustenta que utiliza os recortes de jornais na íntegra do mesmo modo que na art based research são utilizadas as imagens para articular a investigação. Entre os temas que vão fluindo no livro aparecem a caligrafia e a tipografia, verdadeiros estandartes do que poderia ser um modelo inovador de desenho para o ensino da arte (apesar da tradição que o precede), mas vinculando-o às tecnologias de ponta. A escrita é desenho e não podemos eliminar nem a escrita nem a prática do desenho na cultura visual.

O livro é rico de ilustrações nas quais temos a oportunidade de comprovar as ideias que o texto vai expondo, pois resulta fundamental poder conhecer algumas das imagens que acompanham as edições sobre experiências nas Escuelas de Pintura al Aire Libre, que tanto revolucionaram o panorama mexicano. O desenho como descoberta e a paixão por conhecer através do grafismo constituem uma interessante argumentação para seguir considerando esta prática como um encontro positivo com a arte e com a educação. Tudo isso sem nos ampararmos em premissas que possam atender a outros interesses, como quando a autora adverte que: de propostas que não deram certo. (BARBOSA, 2015, p. 54). 
Este trabalho tem muitas narrativas autobiográficas ("minha solidão foi sem drama, imaginativa, cercada de animais"), que nos aproximam dos anseios e das questões que preocupam a pesquisadora. Como narrativa pessoal, articula-se com base na revisão de outros grandes autores, esmiuçando aspectos-chave de cada momento histórico. O título do artigo corresponde precisamente a uma das propostas feitas por Theodoro Braga em um texto publicado em 1923, defendendo uma educação para todas as classes sociais, introduzindo nesta formação integral os aspectos culturais que Ana Mae Barbosa se refere em seu livro na página 114: "Como ensinar-se, por exemplo, o oficio de tipógrafo a educandos que desconheçam o alfabeto?" Pois o mesmo se dá em relação ao ensino da arte, ao conhecimento da história que a precede e às bases que a forjaram.

\section{Referência}

Barbosa, Ana Mae. Redesenhando o desenho: educadores, política e história. São Paulo: Cortez, 2015. 454 páginas.

\section{Ricard Huerta}

É professor de Educação Artística e diretor do Instituto de Creatividad e Innovaciones Educativas da Universitat de València (Espanha). Participa do Grupo de Pesquisa do Observatório de Educación Patrimonial en España (OEPE). Doutor em Belas Artes, licenciado em Música, em Belas Artes e em Comunicação Audiovisual, coordena o projeto Maestros y museos, do qual participam oito universidades de cinco países. É membro do ICOM-Unesco e diretor da Revista EARI - Educación Artística Revista de Investigación. Atuou como professor convidado em universidades de Cuba, Uruguai, Colômbia, Chile e Reino Unido. Publicou livros e artigos em revistas especializadas. Como artista visual tem realizado várias exposições em diferentes países.

E-mail: ricard.huerta@uv.es

Currículo: http://uv.academia.edu/ricardhuerta

Tradução de Gabriela Bon do original em espanhol La capacidad de una luchadora para impulsar la educación artística en Latinoamérica.

Revisão da tradução de Andrea Barrios. 